\title{
The application and accuracy of feature matching on automated cephalometric superimposition
}

\author{
Yiran Jiang ${ }^{1 \dagger}$, Guangying Song ${ }^{1 \dagger}$, Xiaonan Yu' , Yuanbo Dou ${ }^{2,3,4}$, Qingfeng Li ${ }^{2,3,4}$, Siqi Liu ${ }^{1,5}$, Bing Han ${ }^{1 *}$ and \\ Tianmin $\mathrm{Xu}^{1 *}$
}

\begin{abstract}
Background: The aim of this study was to establish a computer-aided automated method for cephalometric superimposition and to evaluate the accuracy of this method based on free-hand tracing.

Methods: Twenty-eight pairs of pre-treatment $\left(T_{1}\right)$ and post-treatment $\left(T_{2}\right)$ cephalograms were selected. Structural superimpositions of the anterior cranial base, maxilla and mandible were independently completed by three operators performing traditional hand tracing methods and by computerized automation using the feature matching algorithm. To quantitatively evaluate the differences between the two methods, the hand superimposed patterns were digitized. After automated and hand superimposition of $T_{2}$ cephalograms to $T_{1}$ cephalometric templates, landmark distances between paired automated and hand $T_{2}$ cephalometric landmarks were measured. Differences in hand superimposition among the operators were also calculated.

Results: The $T_{2}$ landmark differences in hand tracing between the operators ranged from $0.61 \mathrm{~mm}$ to $1.65 \mathrm{~mm}$ for the three types of superimposition. There were no significant differences in accuracy between hand and automated superimposition ( $p>0.05)$.
\end{abstract}

Conclusions: Computer-aided cephalometric superimposition provides comparably accurate results to those of traditional hand tracing and will provide a powerful tool for academic research.

Keywords: Digital imaging/radiology, Orthodontic(s), Cephalometric superimposition, Feature matching, Accuracy

\section{Background}

Since the introduction of cephalometry in 1931 by Broadbent [1], it has become an important tool in clinical diagnosis, treatment planning, evaluation of treatment changes and growth study. The traditional method of cephalometric analysis is hand tracing the craniofacial soft and hard anatomic structural contours on cephalograms on acetate paper. This process is subjective, and the accuracy varies with personal

\footnotetext{
* Correspondence: kqbinghan@bjmu.edu.cn; tmxuortho@163.com

${ }^{\dagger}$ Yiran Jiang and Guangying Song are co-first author.

'Department of Orthodontics, Peking University School and Hospital of

Stomatology, 22 Zhongguancun South Street, Haidian District, Beijing 100081, China

Full list of author information is available at the end of the article
}

experience, knowledge, understanding of craniofacial anatomy and tracking preference [2-6]. Additionally, this process is time-consuming, and the accuracy is also inevitably influenced by the human fatigue level $[7,8]$. In particular, for the purpose of research, a certain number of cephalograms need to be traced and measured within a certain time constraint, and the intra-/inter-reproducibility is impacted.

With the development of digital technology, the traditional hand tracing cephalogram is being replaced by digital cephalometric analysis. In previous studies, the latter method, using commercial software, has been proven to be accurate, reliable and time-saving [8-12]. However, the only exception is the structural superimposition for treatment evaluation

(C) The Author(s). 2020 Open Access This article is licensed under a Creative Commons Attribution 4.0 International License, which permits use, sharing, adaptation, distribution and reproduction in any medium or format, as long as you give appropriate credit to the original author(s) and the source, provide a link to the Creative Commons licence, and indicate if changes were made. The images or other third party material in this article are included in the article's Creative Commons licence, unless indicated otherwise in a credit line to the material. If material is not included in the article's Creative Commons licence and your intended use is not permitted by statutory regulation or exceeds the permitted use, you will need to obtain permission directly from the copyright holder. To view a copy of this licence, visit http://creativecommons.org/licenses/by/4.0/ The Creative Commons Public Domain Dedication waiver (http://creativecommons.org/publicdomain/zero/1.0/) applies to the data made available in this article, unless otherwise stated in a credit line to the data. 
and growth study, although much effort has been made in this field [3, 12-14]. The reason for this exception lies in the fact that landmark identification is easily accomplished using commercial software, while structural superimposition focuses on the tracing of structural details, which is independent of landmarks and is still not feasible using current commercial software.

Baumrind et al. believed that hand superimpositions resulted in better quality than any computer-aided superimpositions, because biological craniofacial growth is difficult to be interpreted by any mathematical equations [2]. However, due to the absolute consistency, fully automated cephalometric analysis has always been a popular challenge in computer science. One of these methods is the knowledge-based line extraction technique [15], which duplicates the strategy of orthodontists by extracting important anatomic edges and locating landmarks according to geometric definitions. However, the irregular details of bone, such as the inter-trabeculae, incisor nerve canal and inferior alveolar canal, make computer automated tracing difficult and questionable. Other studies have attempted to locate landmarks directly $[16,17]$, and the techniques have evolved from template matching [16] to, more recently, neural network models [17]. In terms of structural superimposition on stable regions instead of reference planes, which has been recognised as the most accurate method [18-22], why not use the same strategy?

Feature matching is a computer algorithm [23, 24] whose mission is to detect and match keypoints of the same or similar regions in multiple images taken at different viewpoints, under different illuminations, or at different magnifications. In comparison with the traditional manual process of superimposing the stable structures of two serial cephalograms, this method bears many similarities. One of the algorithms, Oriented FAST and Rotated BRIEF(ORB) [23], was shown to be time-saving for the matching process, rotational-invariant and noise-immune. However, two aspects of this method should be improved for clinical applications: (1) the area for detecting and matching keypoints should be limited to the stable regions on the cephalograms; and (2) to achieve accurate matching results, the matches should be not only abundant but also of high quality.

Currently, studies describing methods for automated cephalometric structural superimposition are scarce. Therefore, the present study aimed to (1) establish a computer-aided automated method of structural superimposition on the anterior cranial base, maxilla and mandible and (2) evaluate its accuracy based on freehand tracing and superimposition.

\section{Methods}

The institutional review board for the protection of human subjects reviewed and approved the research protocol (IRB-201626016).
A total of 28 pairs of pre- $\left(\mathrm{T}_{1}\right)$ and post-treatment $\left(\mathrm{T}_{2}\right)$ cephalograms were selected. They were taken by the same X-ray machine. The subjects consisted of 21 females and 7 males. The age for $T_{1}$ ranged from 12 to 27 years, with a mean age of 15.32 years; the $T_{2}$ ages ranged from 14 to 29 years, with a mean age of 18.03 years. The experimental design is shown in Fig. 1. Calibration rulers were used to control distortions and resolution errors during the printing and scanning process.

\section{Landmark identifications}

One operator identified landmarks on the $T_{1}$ and $T_{2}$ digital lateral films using customised software produced by the State Key Laboratory of Virtual Reality Technology and Systems. The landmarks included the upper reference point (URP), lower reference point (LRP), sella (S), nasion (N), pterygoid point $(\mathrm{Pt})$, posterior nasal spine (PNS), anterior nasal spine (ANS), subspinale (A), supramental (B), pogonion $(\mathrm{Pg})$, menton $(\mathrm{Me})$, gonion $(\mathrm{Go})$, condylion $(\mathrm{Co})$, upper incisor edge (UIE), upper incisor root apex (UIA), upper first molar mesial buccal cusp (UM), upper first molar mesial root apex (UMA), lower incisor edge (LIE), lower incisor apex (LIA), lower first molar mesial buccal cusp (LM), and lower first molar mesial apex (LMA).

\section{Superimposition methodology}

The structural superimposition method developed by Johnston [25] for the anterior cranial base, maxilla and mandible was independently conducted by each operator.

\section{Hand tracing superimposition}

Three senior orthodontic residences, who finished the superimposition course in our department and attended the hands-on lecture given by Johnston in person, were selected as operators in this study. They independently performed hand tracings of $T_{1}$ and $T_{2}$ side by side on acetate paper. Information from the hand superimposition was recorded using a similar method as that developed by the University of California, San Francisco [11]. A series of ten pinholes were drilled into $T_{1}$ films in the non-information-bearing area surrounding the anatomic region of interest. Four corner pinholes on the $T_{1}$ films, called positioning reference pinholes, were used to register the scanned hand tracings onto corresponding digital films. The other six pinholes on the $T_{1}$ films, called superimposing reference pinholes, were used in pairs to register the between-film relationships onto $T_{2}$ tracings for the three types of hand superimposition methods and to convert the between-film relationship of the hand superimpositions into a digital record by scanning. For the $\mathrm{T}_{2}$ films, only the four corner pinholes were drilled. The lateral films with pinholes and the corresponding hand tracings were scanned (HP Color LaserJet 2840, Hewlett-Packard Company, Palo Alto, CA, USA) in 
pre-treatment $\left(T_{1}\right)$ and Post-treatment $\left(T_{2}\right)$ digital lateral films

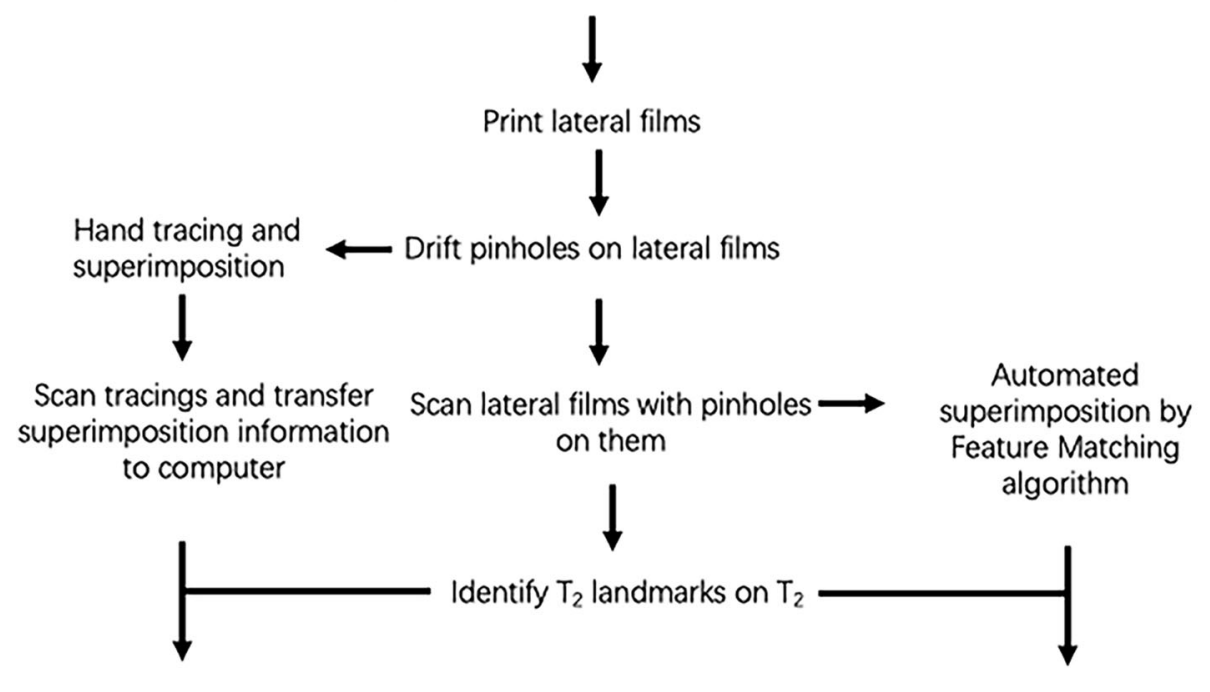

Calculate $T_{2}$ landmark difference $\left(T_{2} L D\right)$ between hand and automated superimposition

Fig. 1 Schematic flowchart of the experimental design

original size and at $600 \mathrm{dpi}$. The operators identified the scanned pinholes that carried the information on superimposition and image size from the $\mathrm{T}_{1}$ and $\mathrm{T}_{2}$ tracings.

\section{Automated superimposition}

Figure $2 \mathrm{a}$ shows the rectangular region of interest enclosed by landmarks on the anterior cranial base, maxilla and mandible used to detect the keypoints. On the anterior cranial base, this area was defined by the URP, S, Pt and N. On the maxilla, this area was enclosed by the Pt, PNS, ANS and A. On the mandible, this area was enclosed by the LM, Pg, Me and Go.

The ORB's oriented FAST algorithm [23, 26] was used to detect keypoints on each confined area. We then used
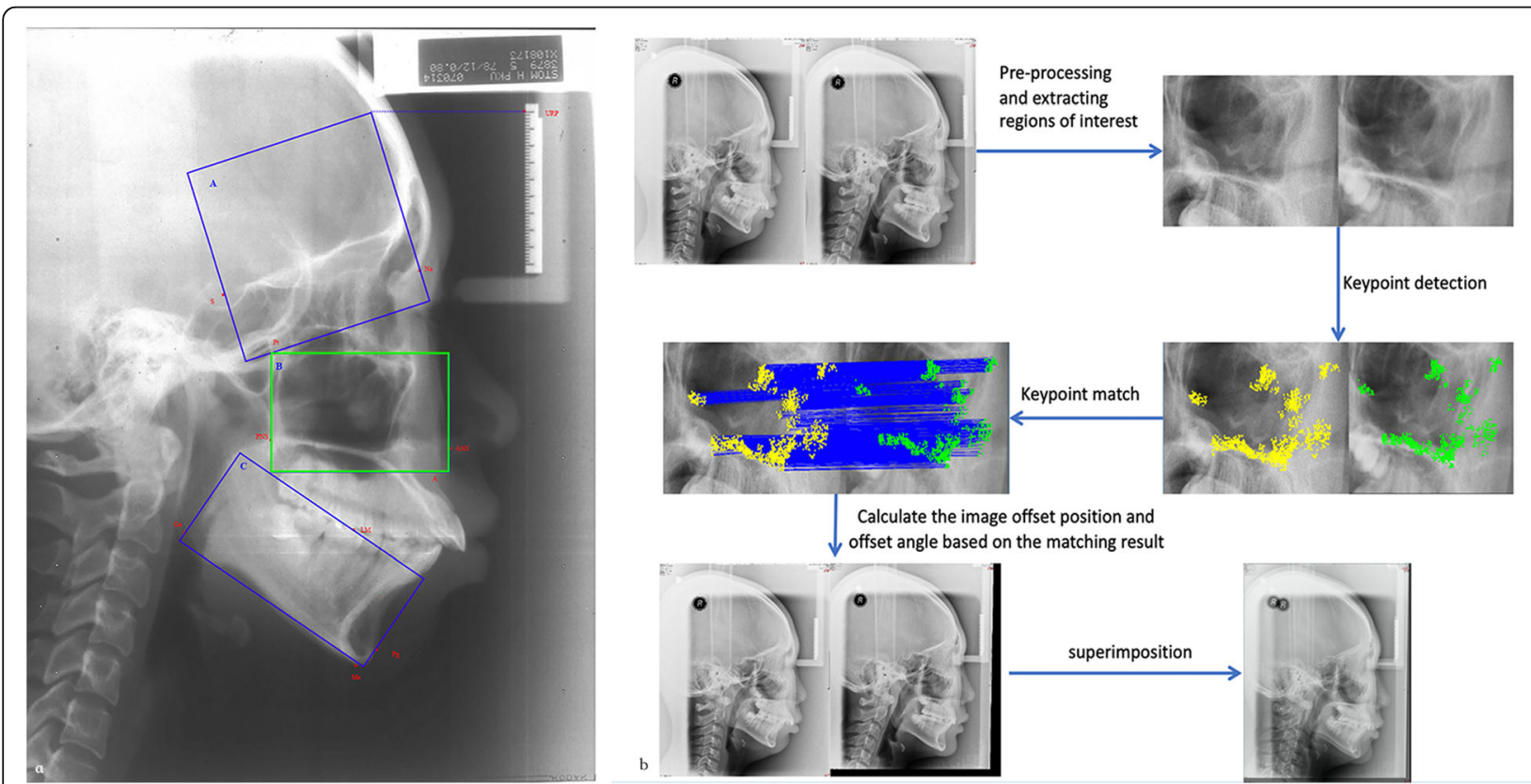

Fig. 2 a The rectangular areas mainly consisting of stable structures were used to detect keypoints enclosed by landmarks on the anterior cranial base, maxilla and mandible. A. Area on the Anterior cranial base: URP-S-Pt-Na. B. Area on the maxilla: Pt-PNS-ANS-A. C. Area on the mandible: LMPg-Me-Go. $\mathbf{b}$ The flowchart of feature matching process and automated superimposition on maxilla 
the ORB's steer BRIEF [23] algorithm for keypoint description, a modified algorithm used to solve the problem that BRIEF is not rotationally invariant. Finally, a brute-force Hamming distance [27] was used to match keypoints on two cephalograms.

Considering that the ORB results might not be completely accurate, the Grid-based Motion Statistics for Fast, Ultrarobust Feature Correspondence (GMS) [24] algorithm was applied to filter the matching results. Then, we calculated the relative offset distances and rotation angles of each pair of successfully matched keypoints and transferred the $\mathrm{T}_{2}$ cephalogram onto the $T_{1}$ image accordingly. The automated superimposition results were exported as Photoshop files.

Figure $2 \mathrm{~b}$ shows the flowchart of the automated superimposition process on maxilla.

\section{Calculation of T2 landmark distances}

Photoshop CC 2017 (Adobe, San Jose, CA, USA) was used to register hand tracings onto the corresponding digital cephalograms. The $\mathrm{T}_{1}$ cephalograms in each automated superimposition file were used as templates to measure the $\mathrm{T}_{2}$ landmark distances $\left(\mathrm{T}_{2} \mathrm{LDs}\right)$. The $\mathrm{T}_{1}$ tracings were registered onto the templates by 4 positioning reference pinholes. To avoid landmark identification errors, one operator used the automatically superimposed $T_{2}$ cephalograms to identify landmarks by the brush tool with a 3-pixel diameter and noted down the landmarks' coordinators as automated superimposition results. Then, the $\mathrm{T}_{2}$ cephalograms were duplicated, and the corresponding $\mathrm{T}_{2}$ tracings were registered on duplicated films at four positioning reference pinholes. Subsequently, they were superimposed onto the templates registered by the bilateral superimposing reference pinholes of the same superimposition type as the automated one. Finally, the landmarks' coordinators on the duplicated $\mathrm{T}_{2}$ cephalograms as the operator's hand superimposition results were noted down. Before importing the next operator's tracings, we deleted the tracings of the previous one to prevent mutual influence of the superimposition results among operators.

To calculate the operative differences of hand superimposition, $\mathrm{T}_{2} \mathrm{LDs}$ between operators' corresponding coordinators were measured (Fig. 3).

Before evaluating hand superimposition accuracy, the average coordinators among three operators' coordinators for each landmark were set as the true values. The $\mathrm{T}_{2} \mathrm{LDs}$ between each operator's coordinators and the corresponding true values were measured.

To evaluate the accuracy of automated superimposition, the $\mathrm{T}_{2} \mathrm{LDs}$ were calculated between the coordinators of automated superimpositions and the corresponding true values.

\section{Statistical methods}

Statistical analyses were carried out with SPSS 25.0 (SPSS Inc., Chicago, IL, USA). The mean $\mathrm{T}_{2} \mathrm{LDs}$ of

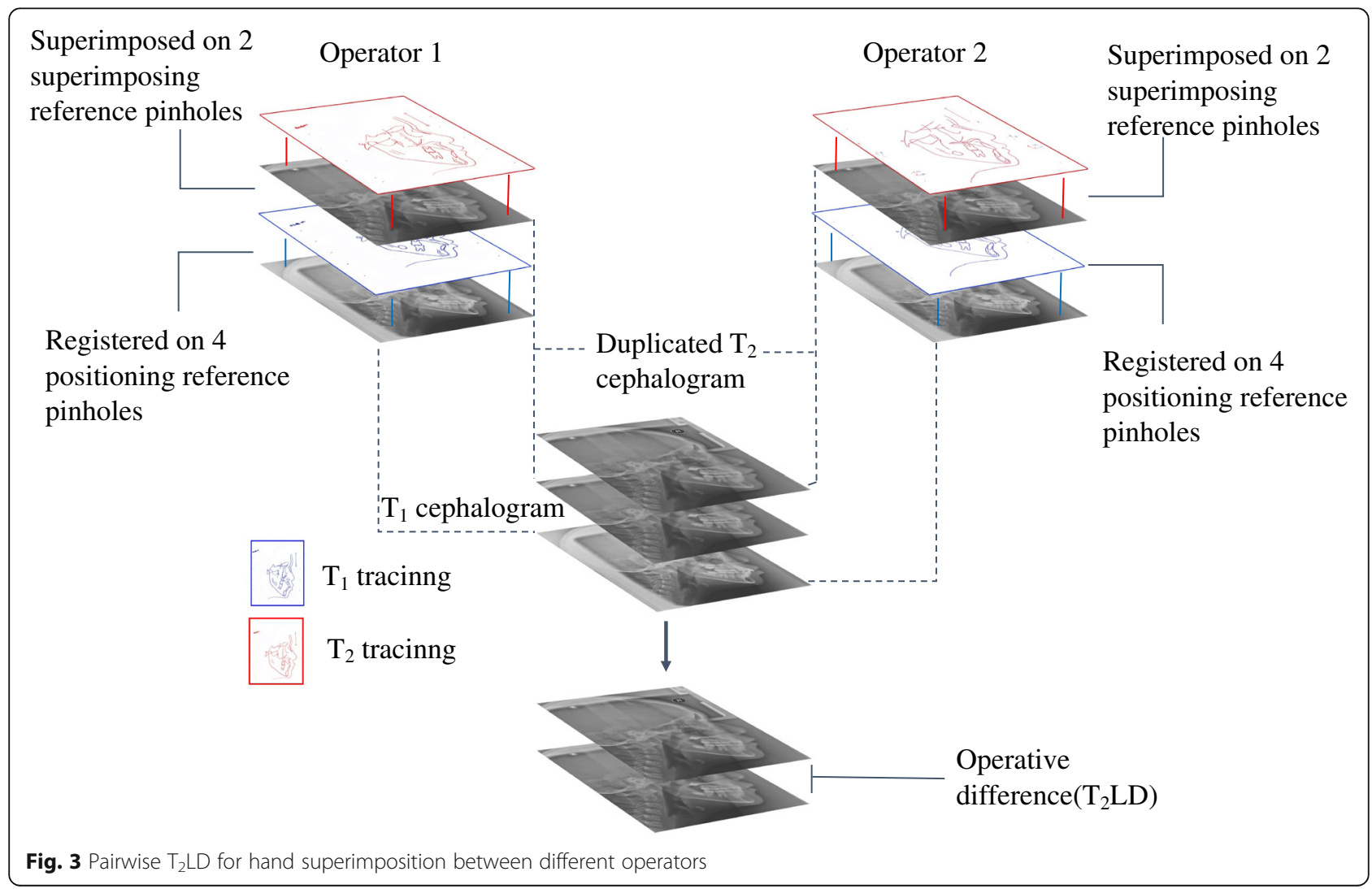


Table 1 Mean operative differences in $T_{2}$ landmark distance $(\mathrm{mm})$ between operators. Paired t-test results for the accuracy between hand and automated superimposition, both compared with true values in cranial base superimposition

\begin{tabular}{|c|c|c|c|c|c|c|c|c|c|}
\hline & $N$ & $\begin{array}{l}\text { Operat } \\
\text { (Hand }\end{array}$ & $\begin{array}{l}\text { ence } \\
\text { (mm) }\end{array}$ & $N$ & $\begin{array}{l}\text { Accura } \\
(\mathrm{mm})\end{array}$ & rocess) & $\begin{array}{l}\text { Accura } \\
(\mathrm{mm})\end{array}$ & process) & $P$-value \\
\hline & & Mean & SD & & Mean & SD & Mean & SD & \\
\hline $\mathrm{Pt}$ & $84^{a}$ & 0.61 & 0.63 & 28 & 0.33 & 0.28 & 0.41 & 0.37 & 0.128 \\
\hline PNS & 84 & 0.69 & 0.65 & 28 & 0.40 & 0.32 & 0.47 & 0.39 & 0.290 \\
\hline ANS & 84 & 0.82 & 0.76 & 28 & 0.47 & 0.38 & 0.54 & 0.45 & 0.313 \\
\hline A & 84 & 0.85 & 0.86 & 28 & 0.50 & 0.42 & 0.59 & 0.54 & 0.274 \\
\hline B & 84 & 0.99 & 0.94 & 28 & 0.58 & 0.46 & 0.59 & 0.48 & 0.880 \\
\hline Me & 84 & 1.02 & 0.96 & 28 & 0.55 & 0.51 & 0.64 & 0.58 & 0.366 \\
\hline Go & 84 & 0.91 & 0.88 & 28 & 0.52 & 0.43 & 0.48 & 0.50 & 0.626 \\
\hline $\mathrm{Co}$ & 84 & 0.67 & 0.68 & 28 & 0.39 & 0.34 & 0.44 & 0.35 & 0.254 \\
\hline
\end{tabular}

${ }^{a}$ Because three operators were compared, a total 28 pairs of cephalograms could yield 84 measurement values

operative differences in hand superimposition, hand superimposition accuracy and automated superimposition accuracy for multiple cephalometric landmarks under each superimposition method were calculated. A paired $t-$ test was applied to examine the statistical accuracy of automated superimposition with hand superimposition. $P$ values less than 0.05 were considered significant.

\section{Results}

The mean $\mathrm{T}_{2} \mathrm{LDs}$ between operators on the anterior cranial base, maxilla and mandible superimposition methods are listed in Tables 1, 2 and 3, respectively. In the anterior cranial base superimposition (Table 1), the mean $\mathrm{T}_{2} \mathrm{LD}$ at the pterygory point showed the least difference ( $\mathrm{Pt}, 0.61 \pm 0.63 \mathrm{~mm}$ ), while the mean $\mathrm{T}_{2} \mathrm{LD}$ at the menton showed the greatest difference (Me, $1.02 \pm$ $0.96 \mathrm{~mm}$ ). In the mandibular superimposition (Table 2), the mean $\mathrm{T}_{2} \mathrm{LD}$ at the condylion showed the greatest difference (Co, $1.65 \pm 1.24 \mathrm{~mm}$ ), and the least difference was observed on the LIE $(0.62 \pm 0.86 \mathrm{~mm})$, followed by the other midline structures (LIA, $0.76 \pm 0.55 \mathrm{~mm}$; B point, $0.75 \pm 53 \mathrm{~mm}$; Pg, $0.75 \pm 0.48 \mathrm{~mm}$; and $\mathrm{Me}, 0.70 \pm$ $0.45 \mathrm{~mm}$ ). However, the operator differences in the maxilla were quite close between the landmarks (Table 3), ranging from $0.78 \mathrm{~mm}$ to $0.82 \mathrm{~mm}$.

The accuracy of automated superimposition on three superimposition methods by the paired t-test is shown in Tables 1, 2 and 3. Hand superimposition showed slightly higher accuracy compared with paired automated superimposition. However, there were no statistically significant differences $(p>0.05)$ between the two operations in all selected cephalometric landmarks of interest.

\section{Discussion}

Decades ago, researchers studying craniofacial growth in the presence of metallic implants advocated superimposing structures that are stable during growth [18-20], and structural superimposition has been verified as the most accurate technique [21, 22]. However, two remaining issues need to be considered. First, in some films with low quality or high complexity due to overlapping structures, it is impossible for orthodontists to determine a sufficient number of stable structures, especially in the maxilla and mandible. Second, if several stable structures do not fit appropriately in the same between-film position, the orthodontists must defer to their biological knowledge and

Table 2 Mean operative differences in $T_{2}$ landmark distance $(\mathrm{mm})$ between operators. Paired t-test results for the accuracy between manual and automated superimposition, both compared with true values in maxillary superimposition

\begin{tabular}{|c|c|c|c|c|c|c|c|c|c|}
\hline & \multirow[t]{2}{*}{$\mathrm{N}$} & \multicolumn{2}{|c|}{$\begin{array}{l}\text { Operative difference (Hand process) } \\
(\mathrm{mm})\end{array}$} & \multirow[t]{2}{*}{$\mathrm{N}$} & \multicolumn{2}{|c|}{$\begin{array}{l}\text { Accuracy (Hand process) } \\
(\mathrm{mm})\end{array}$} & \multicolumn{2}{|c|}{$\begin{array}{l}\text { Accuracy (Automated process) } \\
(\mathrm{mm})\end{array}$} & \multirow[t]{2}{*}{$P$-value } \\
\hline & & Mean & SD & & Mean & SD & Mean & SD & \\
\hline PNS & 84 & 0.79 & 0.60 & 28 & 0.47 & 0.25 & 0.56 & 0.44 & 0.189 \\
\hline ANS & 84 & 0.82 & 0.64 & 28 & 0.56 & 0.37 & 0.57 & 0.44 & 0.855 \\
\hline A & 84 & 0.78 & 0.56 & 28 & 0.54 & 0.34 & 0.53 & 0.45 & 0.889 \\
\hline UIE & 84 & 0.82 & 0.63 & 28 & 0.51 & 0.33 & 0.53 & 0.38 & 0.737 \\
\hline UIA & 84 & 0.80 & 0.58 & 28 & 0.49 & 0.30 & 0.61 & 0.61 & 0.220 \\
\hline UM & 84 & 0.78 & 0.59 & 28 & 0.48 & 0.27 & 0.50 & 0.40 & 0.718 \\
\hline UMA & 84 & 0.80 & 0.60 & 28 & 0.49 & 0.35 & 0.51 & 0.43 & 0.763 \\
\hline
\end{tabular}


Table 3 Mean operative differences in $T_{2}$ landmark distance $(\mathrm{mm})$ between operators. Paired t-test results for the accuracy between manual and automated superimposition, both compared with true values in mandibular superimposition

\begin{tabular}{|c|c|c|c|c|c|c|c|c|c|}
\hline & $\mathrm{N}$ & $\begin{array}{l}\text { Operat } \\
\text { (Hand }\end{array}$ & $\begin{array}{l}\text { ence } \\
\text { (mm) }\end{array}$ & $\mathrm{N}$ & $\begin{array}{l}\text { Accura } \\
(\mathrm{mm})\end{array}$ & rocess) & $\begin{array}{l}\text { Accura } \\
(\mathrm{mm})\end{array}$ & process) & $P$-value \\
\hline & & Mean & SD & & Mean & SD & Mean & SD & \\
\hline$B$ & 84 & 0.75 & 0.53 & 28 & 0.41 & 0.25 & 0.47 & 0.26 & 0.254 \\
\hline $\mathrm{Pg}$ & 84 & 0.75 & 0.48 & 28 & 0.41 & 0.22 & 0.49 & 0.23 & 0.059 \\
\hline Me & 84 & 0.70 & 0.45 & 28 & 0.42 & 0.22 & 0.46 & 0.32 & 0.566 \\
\hline Go & 84 & 1.38 & 1.21 & 28 & 0.74 & 0.49 & 0.72 & 0.39 & 0.836 \\
\hline Co & 84 & 1.65 & 1.24 & 28 & 0.94 & 0.59 & 0.69 & 0.50 & 0.695 \\
\hline LIE & 84 & 0.62 & 0.86 & 28 & 0.52 & 0.36 & 0.58 & 0.30 & 0.538 \\
\hline LIA & 84 & 0.76 & 0.55 & 28 & 0.41 & 0.25 & 0.47 & 0.26 & 0.226 \\
\hline LM & 84 & 1.00 & 0.77 & 28 & 0.52 & 0.33 & 0.58 & 0.29 & 0.401 \\
\hline LMA & 84 & 0.87 & 0.63 & 28 & 0.46 & 0.28 & 0.52 & 0.28 & 0.288 \\
\hline
\end{tabular}

practical experience. Both of these limitations weaken the reliability of hand structural superimposition.

Landmark identifications are the main source of cephalometric errors $[28,29]$. To avoid this type of error and to focus mainly on the reliability and accuracy of superimposition, we carried out our study using film duplication and between-film registration techniques. As shown in Tables 1, 2 and 3, the differences between operators on three types of superimpositions varied greatly from $0.61 \mathrm{~mm}$ to $1.65 \mathrm{~mm}$, a range that was greater than the intra-operator reliability reported by Huja et al. [3]. This finding suggests that the inter-operator variability of superimposition is an important variation of results. In our study, we infer that rotational effects produced a greater number of errors than those produced by translational effects on the superimposition of the anterior cranial base and mandible, which were similar to the results from Baumrind et al. [2] and Cook et al. [6]. However, we also found that the mean $\mathrm{T}_{2} \mathrm{LDs}$ of the six landmarks in the maxillary superimposition were quite similar to each other without showing a progressive trend from any centre. This observation suggests that the translational error may have been the predominant cause of error in maxillary superimposition.

The differences in accuracy between hand and automated superimposition are smaller than the variability among operators but also demonstrate a similar increase in error tendency with spatial patterning on the anterior cranial base and mandibular superimpositions. Although slightly higher accuracy errors were observed on the automated superimpositions, there were no significant differences between the two methods in comparison of the differences in accuracy with the true values determined by the paired t-test. This finding suggests that compared with hand tracing, automated superimposition does not lead to a significant increase in error and has the great advantages of absolute consistency and time-efficiency.
However, a considerable number of high-quality keypoints would favour better accuracy, which relies on the distinction of stable structures from background by a sharp contrast in pixel intensity. An improvement in image quality, along with advancement of the sensitivity for keypoint detection, would solve the problems of this technique.

From a clinical perspective, considering the timeconsuming nature and questionable accuracy of hand cephalometric superimposition when a large number of cases are required for statistical analysis, this automated method could benefit big data analysis using digital cephalograms.

\section{Conclusions}

Computer-aided cephalometric superimposition provides comparable results to those of traditional hand tracing when structural superimposition is concerned. With the help of proper software, this method for digital filmless cephalometry will provide a powerful tool for academic research.

\section{Abbreviations}

A: Subspinale; ANS: Anterior nasal spine; B: Supramental; BRIEF: Binary Robust Independent Elementary Features; Co: Condylion; FAST: Features from Accelerated Segment Test; GMS: Grid-based Motion Statistics for Fast, Ultrarobust Feature Correspondence; Go: Gonion; LIA: Lower incisor apex; LIE: Lower incisor edge; LM: Lower first molar mesial buccal cusp; LMA: Lower first molar mesial apex; LRP: Lower reference point; Me: Menton; N: Nasion; ORB: Oriented FAST and Rotated BRIEF; Pg: Pogion; PNS: Posterior nasal spine; Pt: Pterygoid point; $S$ : Sella; $T_{1}$ : Pre-treatment; $T_{2}$ : Post-treatment; T2LDs: $T_{2}$ landmark distances; UIA: Upper incisor apex; UIE: Upper incisor edge; UM: Upper first molar mesial buccal cusp; UMA: Upper first molar mesial apex; URP: Upper reference point

\section{Acknowledgements}

The manuscript was proofread by a native English professional with a science background at American Journal Experts.

\section{Authors' contributions}

Contribution to conception and design: JYR, SGY, YXN, DYB, LQF, LSQ, HB and XTM; Contribution to data acquisition and interpretation: JYR and SGY; Contribution to performance of all statistical analyses: JYR; Contribution to 
drafting of manuscript: JYR and DYB; Contribution to critical revision of manuscript: SGY, YXN, LQF, LSQ, HB and XTM. All authors read and approved the final manuscript.

\section{Funding}

This study was financially supported by the Beijing Nature Science Foundation (7192227) to establish the method for automated superimposition, by the National Natural Science Foundation of China (51972005, 51672009) and the Research Foundation of Peking University School and Hospital of Stomatology (PKUSS20190115) for sample collection and data acquisition.

\section{Availability of data and materials}

The full datasets used and analysed during the current study are available on reasonable request from the corresponding authors at tmxuortho@163.com and kqbinghan@bjmu.edu.cn.

\section{Ethics approval and consent to participate}

The institutional review board for the protection of human subjects reviewed and approved the research protocol (IRB-201626016).

\section{Consent for publication}

Not applicable.

\section{Competing interests}

The authors declare that they have no competing interests.

\section{Author details}

${ }^{1}$ Department of Orthodontics, Peking University School and Hospital of Stomatology, 22 Zhongguancun South Street, Haidian District, Beijing 100081, China. ${ }^{2}$ State Key Laboratory of Virtual Reality Technology and Systems, School of Computer Science and Engineering, Beihang University, Beijing, China. ${ }^{3}$ Beijing Advanced Innovation Center for Big Data and Brain Computing (BDBC), Beihang University, Beijing, China. ${ }^{4}$ Hangzhou Innovation Research Institute, Beihang University, Beijing, China. ${ }^{5}$ First Clinical Division, Department of Orthodontics, Peking University School and Hospital of Stomatology, Beijing, China.

Received: 2 December 2019 Accepted: 12 March 2020 Published online: 19 March 2020

\section{References}

1. Broadbent BH. A new x-ray technique and its application to orthodontia. The introduction of cephalometric radiology. Angle Orthod. 1931;1(1):45-66.

2. Baumrind S, Miller D, Molthen R. The reliability of head film measurements: 3. Tracing superimposition. Am J Orthod. 1976;70(6):617-44.

3. Huja SS, Grubaugh EL, Rummel AM, Fields HW, Beck FM. Comparison of hand-traced and computer-based Cephalometric superimpositions. Angle Orthod. 2009;79(3):428-35.

4. Gilddon MJ, Xia JJ, Gateno J, Wong HTF, Lasky RE, Teichgraeber JF, Jia XL, Liebschner MAK, Lemoine JJ. The accuracy of Cephalometric tracing superimposition. J Oral Maxillofac Surg. 2006;64(2):194-202.

5. Roden-Johnston D, English J, Gallerano R. Comparison of hand-traced and computerized cephalograms: landmark identification, measurement, and superimposition accuracy. Am J Orthod Dentofac Orthop. 2008; 133(4):556-64

6. Cook PA, Gravely JF. Tracing error with Björk's mandibular superimposition Angle Orthod. 1988;58(2):169-78.

7. Tsorovas G, Karsten AL. A comparison of hand-tracing and cephalometric analysis computer programs with and without advanced feature accuracy and time demands. Eur J Orthod. 2010;32(5):721-8.

8. Yue WN, Yin DL, Li CJ, Wang GP, Xu TM. 2006. Automated 2-D Cephalometric analysis on $\mathrm{X}$-ray image by a model-based approach. IEEE Trans Biomed Eng. 2006;53(8):1615-23.

9. Chen YJ, Chen SK, Yao JC, Chang HF. The effects of differences in landmark identification on the cephalometric measurements in traditional versus digitized cephalometry. Angle Orthod. 2004;74(2):155-61.

10. Ongkosuwito EM, Katsaros C, van't Hof MA, Bodegom JC, Kuijpers-Jagtaman AM. The reproducibility of cephalometric measurements: a comparison of analogue and digital methods. Eur J Orthod. 2002;24(6):655-65.
11. Baumrind S, Miller D. Computer-aided head film analysis: the University of California san Francisco method. Am J Orthod. 1980;78(1):41-65.

12. Polat-Ozsoy O, Gokcelik A, Toygar Memikoglu TU. Differences in cephalometric measurements: a comparison of digital versus hand-tracing methods. Eur J Orthod. 2009;31(3):254-9.

13. Jacquet W, Nyssen E, Bottenberg P, de Groen P, Vande VB. Novel information theory based method for superimposition of lateral head radiographs and cone beam computed tomography images. Dentomaxillofac Radiol. 2019;39(8):191-8.

14. Nabipour S, OH H, Boyd R, Baumrind S. Comparative reliability of cephalometric superimpositions: computer monitor versus acetate standard. IADR Thursday, March 17, 2011: 3:30 p.m. -4:45 p.m.

15. Lévy-Mandel AD, Venetsanopoulos AN, Tsotsos JK. Knowledge-based landmarking of cephalograms. Comput Biomed Res. 1986;19(3):282-309.

16. Cardillo J, Sid-Ahmed MA. An image processing system for locating craniofacial landmarks. IEEE Trans Med Imaging. 1994;13(2):275-89.

17. Arik SÖ, Ibragimov B, Xing L. Fully automated quantitative cephalometry using convolutional neural networks. J Med Imaging (Bellingham). 2017;4(1): 014501.

18. Bjork A, Skieller V. Roentgencephalometric growth analysis of the maxilla. Trans Eur Orthod Soc. 1977;7:209-33.

19. Bjork A. Facial growth in man studied with the aid of metallic implants. Acta Odontol Scand. 1955;13(1):9-34.

20. Bjork A. Variations in the growth pattern of the human mandible: longitudinal radiographic study by the implant method. J Dent Res. 1963; 42(1):400-11.

21. Nielsen IL. Maxillary superimposition: a comparison of three methods for cephalometric evaluation of growth and treatment change. Am J Orthod Dentofac Orthop. 1989;95(5):422-31.

22. Gu Y, McNamara JA Jr. Cephalometric superimpositions. Angle Orthod. 2008;78(6):967-76.

23. Rublee E, Rabaud V, Konolige K, Bradski GR. ORB: an efficient alternative to SIFT or SURF. IEEE International Conference on Computer Vision, ICCV 2011. Barcelona: IEEE; 2011.

24. Bian JW, Lin WY, Matsushita Y, Yeung SK, Nguyen TD, Cheng MM. GMS: grid-based motion statistics for Fast, ultra robust feature correspondence. 2017 IEEE Conference on Computer Vision and Pattern Recognition (CVPR). Honolulu: 2017. p. 2828-37.

25. Johnston LE Jr. Balancing the books on orthodontic treatment: an integrated analysis of change. Br J Orthod. 1996;23(2):93-102.

26. Rosten E, Drummond T. Machine learning for highspeed corner detection. In: Computer Vision-ECCV; 2006. p. 430-43.

27. Al-Okaily A. Error tree: a tree structure for hamming \& edit distances \& wildcards matching. J Comput Biol. 2015;22(12):1118-28.

28. Baumrind S, Frantz RC. The reliability of head film measurements:1. Landmark identification. Am J Orthod. 1971;60(2):111-27.

29. Baumrind S, Frantz RC. The reliability of head film measurements:2. Conventional angular and linear measures. Am J Orthod. 1971;60(5):505-17.

\section{Publisher's Note}

Springer Nature remains neutral with regard to jurisdictional claims in published maps and institutional affiliations.

Ready to submit your research? Choose BMC and benefit from:

- fast, convenient online submission

- thorough peer review by experienced researchers in your field

- rapid publication on acceptance

- support for research data, including large and complex data types

- gold Open Access which fosters wider collaboration and increased citations

- maximum visibility for your research: over $100 \mathrm{M}$ website views per year

At $\mathrm{BMC}$, research is always in progress.

Learn more biomedcentral.com/submission 